\title{
EFL Learners' Language Proficiency and Their Performance on (Non) Literary Inference Demanding Tests
}

\author{
Reza Mokhtari \\ Islamic Azad University, Science and Research Branch, Kermanshah, Iran \\ Natasha Pourdana \\ Gyeongju University, Republic of Korea \\ Omid Varzandeh \\ Islamic Azad University, Sanandaj Branch, Iran
}

\begin{abstract}
The present study aimed to explore whether there is any relationship between the performance of EFL learners on inference demanding tests of (non)literary text and their English language proficiency. Through convenience method of sampling, 30 Iranian senior students of English translation B.A. both of male and female genders, ranging from 19 to 30 years of age took part in the investigation. Once their language proficiency was measured by means of Oxford Placement Test, participants took part in an inferencing test constructed by the researcher consisting of two cloze tests - one non-literary and one literary text. The results of the test of Pearson Product-Moment Correlation Coefficient revealed that there was a positive and strong relationship between the learners' language proficiency and their ability in answering inferencing questions. This study is particularly important as most reading materials are far from being shallow and require deep interpretation.
\end{abstract}

Index Terms-EFL, proficiency, literary text, non-literary text, inference

\section{INTRODUCTION}

Reading is indispensable to academic, social and financial success. However, in practice, reading comprehension has not been in the center of attentions. Since the clarification of the complexities in reading comprehension remains vague, and since it is reckoned that reading comprehension is an intricate behaviour that continues to be bewildering, one may not set about analysing it in its wholeness. Therefore, it seems critical to study particular aspects of the process as a means of pursuing progression in the assessment of the entire procedure in reading comprehension. Therefore, it would be highly beneficial to offer an account of existing research and practice in the field of Literature and language teaching with special but not exclusive reference to EFL material development in foreign language studies.

There is more to reading than applying skills and analysing texts and learners need not only to decode the text but also to think through, experience while anticipating, questioning, puzzling over, and imagining it. However, many EFL teachers attempt to emphasize immediate and direct components of reading passage. Pennell (2002) concluded that very little attention is given to teaching students the strategies of reading comprehension and the teachers' assessment addresses students understanding rather than teaching them how to comprehend. Thus, one of the many problems students face nowadays is poverty of explicit comprehension strategy instruction on the side of EFL teachers.

The pressing problem here is that most materials used in the field of language learning are far from being shallow. They notably require EFL learners to process a text based on their own prior knowledge and reasoning to fill in the intentional gaps the author wishes readers to. In other words, EFL readers highly need inference making ability to comprehend fully and interact with the passage. It is with the practice of inference as a phase of reading comprehension that this study is most concerned.

What EFL teachers should, therefore, bear in mind is that it may not be the English language (i.e., a linguistic factor) that impedes successful reading comprehension; rather, it may be the EFL learners' unfamiliarity with content of the text. EFL teachers and material developers should therefore provide relevant information to their students so that they better comprehend the texts, and such information can be easily accessed through literary texts. A major justification is that literary texts are life-like and of great pleasure or relevance to student's everyday life. Appropriateness of integrating literature in EFL/ESL teaching is recognized by several authors and researchers (Bagherkazemi \& Alemi, 2010; Bhuvanesvari \& Jacob, 2011; Carter, 1997; Duff \& Maley, 2003; Gajdusek, 1988; Khatib, Rezaei, \& Derakhshan, 2011; Lazar, 1994; McKay, 1982; Savvidou, 2004). The current study, thus, is based on this hypothesis that not only is literature a source of individual delight, but also a ingenious language learning instrument that helps EFL learners infer 
veiled ideas between the lines. This research, thus, seeks to find if there is any relationship between EFL learners' language proficiency and their performance on inference demanding tests.

\section{LITERATURE REVIEW}

\section{A. Literature and Language Instruction}

Rationalizations for the merging literary texts with EFL/ESL classrooms are abundant and the great number of researchers, and instructors who have written and applied literature in defence of such integration tells its own tale. The bases for such choice are almost universal among many, and the following will be an account of the most favourable ones.

Among the many reasons to embed literature in the teaching of language, Khatib et al. (2011) have named motivation as a great factor. Learning a language serves a purpose and according to Bhuvaneswari and Jacob (2011) the most salient one is to make the learners learn the language and use it infallibly. They also went on to claim:

This is done best when the learners are involved actively in the learning process. Involvement comes only if sufficient interest is aroused and sustained in the classroom....Catering to the needs of the second language learners, the syllabus should be revised and the curriculum should include short stories which will evince keen interest among the second language learners. (p. 156)

In his article on using literature in EFL classes, Aguero (n. d.) held that "Helping students see how literature relates to their lives usually makes them like literature" (p. 4). Mackay (1982), to further support the use of literature in EFL/ESL classroom, has argued that students take pleasure in reading literary text as it can motivate them to interact with the text which in turn may increase their reading proficiency. Motivation is reckoned as a major feature in literary text based on Duff and Maley's (1990) assumption.

One instance of a literary genre which has abundantly referred to as a great source for reading in EFL classes and that serves as a great source of motivation is short story. What makes stories especially interesting in Erkaya's term was "Since short stories usually have a beginning, middle and an end, they encourage students at all levels of language proficiency to continue reading them until the end to find out how the conflict is resolved" (p. 5). This is captured best by Bhuvaneswari and Jacob (2011) as such literary text is interesting and short enough to minimise the distraction level thus, focused attention rises and consequently lexical and structural complexities are simpler to comprehend.

Culture, in its broad sense, might help the language learners in different directions and thus functions as an alternative reason for incorporation of literature in EFL instruction. Several scholars have compromised such idea. Zoreda and Lima (2008) stated that literature can greatly help introduce the features of U.S. and British culture while expanding the Language learners' ability to read in a foreign language. In addition, it removes the dark perspective EFL learners might have toward the target language culture. This is especially important when we consider this attitude as barriers on the way of acquiring a new language (as cited in Bagherkazemi \& Alemi, 2010). Merits of acquiring cultural knowledge through use of literature in EFL/ESL syllabus were looked at from a different angle by Ronnqvist and Sell (1994):

Reading literature not only gives learners a chance to contextualize on the basis of the cultural knowledge they already have, but can encourage them to use their brains in an effort to acquire the new knowledge they need in order to understand passages which puzzle them. By using and acquiring cultural information in this way, foreign language learners are in fact behaving like members of the target community, and it is reasonable to hope that for some learners the reading of target-language literature will stimulate the development of an integrative motivation in their learning. (p. 125)

McKay, too, recognizes how valuable literature is to enhance the tolerance of language learners concerning the cultural differences which in turn might trigger language learners to create their own imaginative works (1982). This question might seem critical to answer that whether there is any use in indulging one in world of imagination where there is no right or wrong, the kind of world where all seem to be equally good. The response to such question was best captured in Frye's term (1964, as cited in McKay, 1982) holding that "One of the most obvious uses, I think, is its encouragement of tolerance" (p. 531).

Another common cited rational for the use of literature is its contribution to linguistic knowledge. On their list of the reasons why literature is highly useful in foreign language setting, Khatib et al. (2011) have called literary texts specifically novels and dramas as good extensive and poetry as great intensive reading practice. They also continue to claim that literature serves as a good ground for writing practice. They are not alone there though. Thom (2008) equally has claimed that literary text can give EFL learners plentiful chances "to use and develop such sub skills as deduction of meaning from linguistic and situational context, relating text to knowledge and experience of the world, responding to text, creative writing, etc." (p. 122). One possible reason for such fruitfulness as a resourceful language teaching instruments is perhaps best explained by Gajdusek (1998) who believed that literary texts have "internal coherence" which makes interpretation of them rather simpler. In addition, literature benefits from "conscious patterning" which implies the pattern of any literary text is to connect intellectual, emotional and physical experiences.

Literature is a multi-faceted field in which authenticity is a critical aspect. Thornbury (2006) has defined authentic texts as "A classroom text is authentic if it was originally written for non-classroom audience. A newspaper article and pop song are thus considered authentic, whereas a coursebook drill or dialogue is not" (p. 21). Savvidou (2004), to press 
the significance of authentic contents and specifically literary ones, claimed inseparability of literature and language and named headlines and advertisements as common examples of discourse which exploit literary language. One author and researcher who has backed the use of authentic materials in English language teaching (ELT) is Widdowson:

If you are going to teach real English as it functions in contextually appropriate ways, rather than a collection of linguistic forms in contrived classroom situations, then you need to refer to, and defer to, how people who have the language as an Ll actually put it to communicative use. (1996, p. 67)

Bagherkazemi and Alemi (2010) cited Van (2009) as claiming that authenticity provides the basis for meaningful context to improve the understanding and inference ability in EFL learners. Such ideas pave the way for considering longer term goals of acquiring language. McKay (1982) named one major aim of acquiring language as:

The question is one of whether or not the study of literature can in any way contribute to academic and/or occupational goals. Certainly, in so far as literature can foster an overall increase in reading proficiency, it will contribute to these goals ... For some students, literature may provide the affective, attitudinal and experiential factors which will motivate them to read. As such literary texts can aid in the development of reading proficiency and in this way contribute to students' academic and occupational objectives. (p. 530)

As indicated, justifications for utilising literature in EFL classrooms are numerous and they can all be found summarised by Van (2009, as cited in Bagherkazemi \& Alemi, 2010) who has pointed out a number of reasons why literature is highly fruitful in EFL classroom:

- It provides meaningful contexts;

- It involves a profound range of vocabulary, dialogues and prose;

- It appeals to imagination and enhances creativity;

- It develops cultural awareness;

- It encourages critical thinking;

- It is in line with CLT (Communicative Language Teaching) principles.

Selection of literary text is another major consideration in EFL program since each kind might serve different functions and our criteria should be in line with those purposes (McKay, 1982; Povey, 1967; Thom, 2008). But, prior to selection of any literary text one must identify its main distinguishing features from that of non-literary.

Carter (1997) considered all languages literary, some more literary than some others. He has also proposed some criteria for specifying literariness in language: (1) Literary language is medium dependent since it creates a world of internal reference and depends only on its own power to project. (2) Literary language enjoys the notion or reregistration which means such language welcomes any register, style, or word. (3) Interaction of level or semantic density is another feature of literary language. That is to say, interaction of numerous overlaid codes and levels is considered as more literary than a text where there are fewer number of levels at work or where they are present but do not interact as densely. (4) Each word in literary language might possess more than one meaning. (5) Interaction of author and reader is another criterion specific to more literary texts. This is named as displaced interaction. (6) Final feature of more literary languages is discourse patterning at supra-sentential level (pp. 129-135). Discourse types, in Kinneavy's view, are expressive which concentrates on personal expression (letters, diaries, etc.), transactional, focusing on passage and reader (advertising, instructions, etc.), and poetic, that presses the significance of form and language (short story, novel, drama, poetry, etc.) (1983, as cited in Savvidou, 2004).

ome guidelines for choosing literary genres, according to Nga (2003), are appropriateness, cultural barriers, and pleasure. By appropriateness, the level of difficulty in terms of grammar, lexis, and style in connection with language proficiency is intended. Another factor to choose a text of literary taste would be the learners' difficulty in dealing with unknown cultural aspects. And finally provided that readers enjoy what they read, greater understanding and interpretation of text will be achieved (as cited in Thom, 2008).

Text type can be chosen and used according to the local classroom needs such as language teaching and learning objectives, learners' target language proficiency level and accessibility of each text type. McKay (1982) has called attention to young adults as they are mostly not in an appropriate level to read current literature. She suggested taking readability into accounts while choosing a literary text. An alternative way is to select literary work which is written for this age range. Khatib and Nourzadeh (2011) cited Hadaway and Young (2006) as enumerating the factors in six criteria:

- Content accessibility: Is the topic familiar?

- Language accessibility: Is the language used in proper level of difficulty?

- Visual accessibility: Are there enough illustrations?

- Genre accessibility: Are different genres available?

- Cultural accessibility: Is the text culturally related to the EFL learners' lives?

- Accuracy and organization accessibility: Is the text properly organized?

\section{B. Literature and Inference}

Interdependency of literary texts and inferring ability best manifests itself in the definitions scholars have made about inference. Keene and Zimmermann (1997, as cited in Kopitski, 2007) in their try to explicate inference defined the term as "when we read, we stretch the limits of the literal text by folding our experience and belief into the literal meanings 
in the text, creating a new interpretation, an inference" (p. 147). In line with such description, Beers (2003, as cited in Kopitski, 2007) also held that "an inference is the ability to connect what is in the text with what is in the mind to create an educated guess" (pp. 61-62). Both definitions stress the role of interaction between the reader's prior knowledge and a given text. Considering aforementioned controversies, the importance of literary texts seems even more obvious.

Inference is not limited to reading comprehension; there are several moments in everyday life when one needs to infer and draw conclusions since inferring is about reading faces, gestures, tone as well as reading text. One instance of inference in everyday life is joke. Jokes are funny because of the implied meaning understood by the teller and the audience. A joke is told when the teller has a presupposition that there is a shared knowledge between the teller and the listener; otherwise there would be nothing funny in the statement. In order to infer the intended meaning of the joke teller, the listener combines the clues in the joke with the information he/she already has.

There has been consensus over whether comprehension skill correlates with inference ability. Cain et al. (2001) suggested:

Even when knowledge was equally available to all participants, poor comprehenders build incomplete representations of the text: They are often able to integrate information at a local level but are unable to produce a coherent integrated model of the text as a whole. Poor comprehenders' difficulties with inference making are a likely cause of their text-level comprehension problems. (p. 857)

In the same study, the authors point out the skilled comprehenders' ability to read more as a key factor to acquire more information which in turn leads to superior inference making compared to poor comprehenders. Walls (1986) summarized the reasons why good readers draw more inferences compared with poor ones: Firstly, they possess a more extensive prior knowledge. Secondly, they enjoy a higher intelligence and a better memory capacity. Finally, their cognitive learning style is field independent. Kispal (2008), on the other hand, enumerated the reasons why poor comprehenders fail to make viable inferences, if any. It is supposed that they are less aware:

- that a text should make sense to them

- that they should be monitoring their understanding for potential inconsistencies

- about strategies to adopt when embarking on a text

- about strategies to adopt when an inconsistency occurs

- about the need to draw inferences at all

- about the information that is relevant to the drawing of inferences

A comprehensive study of inference types is carried out by Kispal (2008) who has cited the most frequent inferences, reckoning some overlaps between them:

- Coherence inferences (also known as text-connecting or inter-sentence inferences): Integrity of text is sustained through these types of inference. For instance, in the sentence Mary asked her friend to shoulder the responsibility, the reader will recognise that the pronoun 'her' addresses Mary to fully grasp the meaning of the text.

- Elaborative inferences (also known as gap-filling inferences): Mental representation of the text is augmented through these types of inferences. For example, in the sentences "As soon as Susan saw the criminal, she called the police," the reader will make use of life experience and general knowledge to understand that the police would arrest the criminal to supply the connection between these sentences.

- Local inferences: These create a coherent representation at the local level of sentences and paragraphs. This class of inferences includes:

1. Coherence inferences (described above).

2. "Case structure role assignments", e.g. Dan stood his bike against the tree. The reader needs to realise that the tree is assigned to a location role.

3. "Antecedent causal" inferences, e.g. He rushed off, leaving his bike unchained. The reader would need to infer that Dan was in a hurry and left his bicycle vulnerable to theft.

- Global inferences: These types address the entire text to create coherence. The reader should infer overarching notions regarding the theme, main point or moral of a text by relying on local pieces of information.

- On-line inferences: These include making inferences automatically while reading.

- Off-line inferences: These include making inferences strategically after reading.

Pennell (2002) cited Barrett (1974) as describing eight kinds of inference: Inferring supporting details: Guessing further facts the author could have included in the text to make it more informative, and attractive. Inferring the main idea: Finding out the theme, or moral that is not explicitly stated in the text. Inferring sequence: Speculating what event may have taken place between two explicit incidents or hypothesising about what could happen next. Inferring comparisons: surmising similarities and differences in characters, times, or places. Inferring cause-and-effect relationships: Inferring the motives of characters and their interactions with others and with time and place. Inferring character traits: Hypothesizing about the nature of characters based on the explicit clues in the text. Predicting outcomes: Guessing the outcome of a text after reading the beginning part of it. Inferring about figurative language: Inferring literal meanings from the author's figurative use of language.

Walls (1986) cited Schank (1975) as classifying inferences into slot-fulfilling and text-connecting types. Slotfulfilling inference reproduces a hidden act or event in a text; such inference highly needs background knowledge. Text- 
connecting inference elucidates relationship between explicit acts and events which heavily depends on linguistic knowledge. Frederiksen (1976, as cited in Walls, 1986) has categorized inferences in terms of operations:

- Lexical class: understanding pronoun referents and specific meanings of multiple meaning words.

- Identification class: Inferences involving attributes, location, degree and time that are necessary for identifying persons, objects, places and events.

- Frame class: Inferences related to instruments, results, goals, sources, themes and acts.

- Event class: It involves inferring events.

- Algebraic class: It involves inferences of quantity.

- Truth value class: Inferences requiring that a judgment be made on the truth or falsity of a situation.

- Macrostructure class: Inferring superordinate and subordinate relationships and ideas in a text.

- Dependency class: It deals with inferences of a causal and conditional nature.

\section{Methodology}

This section outlines the steps taken in the process of carrying out the study. Detailed report will address the introduction to the participants, instruments, and the procedures employed in data collection. Finally, a thorough data analysis entails the report. The following research question is the focus of this study: Is there any relationship between EFL learners' language proficiency and their performance on inference demanding tests?

\section{A. Participants}

The sample in this study was made up of 30 male and female Iranian senior university students of English translation B.A., studying at Islamic Azad University, Karaj Branch, Iran, ranging from 19 to 30 years of age. The convenience method of sampling was utilised. All participants had passed a nationwide university entrance exam to be eligible for admitting in the aforementioned university and had attended reading comprehension courses during the past 6 semesters. The sample was true representative of the entire population given that they were all majoring at an English language major. Oxford Placement Test (OPT) was administered to homogenize the attendants based on their general language proficiency. Participants whose scores on OPT were beyond the range of \pm 2 standard deviation from the mean (56.77) were set to be discarded; however, Kolmogorov-Smirnov test indicated a normal distribution of scores.

\section{B. Instrumentation}

Two tests contents were developed and administered. A validated test of language proficiency (Oxford Placement Test), retrieved from www.oup.com, was administered as a means of homogenizing the participants in terms of their language proficiency. The test consists of 60 multiple-choice items. An analytic look at the test suggests that language components tested were grammar, vocabulary, as well as English reading comprehension. The allotted time for all 60 items was 30 minutes with 5 extra minutes to transfer the answers to the answer sheets. An answer sheet was devised to ease the process of correction.

A cloze test including 47 multiple-choice items was constructed by the researcher. The test consisted of a non-literary text with 24 items and a literary text (poetry) with 23 items. Two texts were stapled together as the booklet form. In order to determine whether the items that appeared in the inference demanding test were of proper functioning quality, it was vital for the cloze tests to be piloted and revised. The total test can be found in appendix A.

The purpose of this process was to screen the malfunctioning items so that the most suitable distractors would be included in the final version of the cloze test. The researcher included six alternatives in each item. After the pilot administration, the items were thoroughly analysed. After item analysis, those four alternatives that had the best discrimination index values were selected for every 47 items and the residue was discarded.

The non-literary passage entitled as "why the Yogic way for food?" was chosen from the book Essential Reading for IELTS (Gordon \& Harding, 2007) with a readability of 19.80. The poetry is chosen from one of the collections of Maya Angelou under the name Phenomenal Woman (1978).

Poetry is a type of text where imagination and figurative language dominates which in turn undermines the validity of readability formulas. Therefore, it was decided that the best way to control the poem's difficulty and readability would be to ask 15 EFL teachers for their reflection on the text difficulty. Twelve out of 15 felt the two texts were almost of the same difficulty. It was further supported with piloting the test on 10 upper-intermediate EFL language learners who were studying Summit 1A from Top Notch series. Four of the test takers claimed that the poem was more difficult than the prose.

Through test piloting, a sufficient test time was determined ( 35 minutes). The reason why poetry is chosen among a long list of literary genres and styles is the fact that poetry is symbol of literariness in literature which could best carry the aims of the present study. The questions for both texts were devised in a way that their alternatives directly tested the test takers' inference making ability.

Participants' inference ability was tested against these misleading factors; some of which might have triggered them to choose the correct response which was considered as one of the research imposed limitations. The alternatives marked as 'close' could equally be replaced by the correct response; however, participants' ability to guess, infer and retrieve the original response was desired. 
TABLE I

SPECIFICATIONS OF INFERENCE CLOZE TEST

\begin{tabular}{|c|c|c|c|c|c|c|c|c|c|c|}
\hline Test & Words & Items & $\begin{array}{l}\text { Too } \\
\text { Informal }\end{array}$ & $\begin{array}{l}\text { Too } \\
\text { Formal }\end{array}$ & Close & Grammar & $\begin{array}{l}\text { Wrong } \\
\text { Word } \\
\text { Choice }\end{array}$ & $\begin{array}{l}\text { Background } \\
\text { Knowledge }\end{array}$ & Context & Rhyme \\
\hline $\begin{array}{l}\text { Non- } \\
\text { literary }\end{array}$ & 213 & 24 & 9 & 4 & 47 & 30 & 17 & 6 & 5 & 1 \\
\hline Literary & 189 & 23 & 5 & 11 & 33 & 16 & 23 & 1 & 6 & 0 \\
\hline
\end{tabular}

Alternatives for these two tests were too informal, too formal, grammatically incorrect, or wrong word choice. Some other factors affecting the responses were considered as the test takers' background knowledge, context familiarity, and rhyme perception.

\section{Test Administration Procedure}

The researcher utilised OPT to place the participants in a range of two standard deviations below and above the mean (56.77). Before administering the test and after the distribution of test booklets as well as answer sheet, the researcher explained the instructions in participants' native language (Persian). After 35 minutes, they were asked to put their pencils down and all booklets recollected for data analysis.

A week later, the inference test was administered. The test composed of one non-literary and one literary cloze test, each with 24 and 23 multiple-choice items respectively. The two cloze passages were in the same booklet. The text length for the non-literary passage was minimally longer which in turn demanded more time to be answered. The Persian test instruction was provided in the test booklet. Participants collectively finished on time which itself suggested the sufficiency of time allotted. Finally, by analyzing the gathered data from the remaining booklets, and parametric testing of the statistical significance for the hypothesis, the researcher tried to testify the research hypothesis.

\section{RESULTS AND DisCUSSION}

The tests administered among all participants were scored by the researcher. In the placement and inference tests, every true response to each item was awarded 1 point; while, for each item that was unmarked or marked erroneously, zero score was assigned. Since the number of questions varied among the test and that the researcher intended to come to a correlation between them, percentage of each score would act as a true indicator of values. Different statistical procedures were performed for the analysis of the scores. Measures of central tendency including mean scores and standard deviations of the placement and inference tests were tabulated.

The data were undertaken test of normality to decide on the parametric/nonparametric tests. To study the relationship between the proficiency level of the participants and their general performance on both literary and non-literary tests, the participants' test scores were input to SPSS and Pearson Product Moment Correlation Coefficient (PPMCC) was conducted.

Figure 1 shows the frequency of the scores obtained in the test. It can be seen from the figure that scores of two test takers were below 40 and accumulation of scores is between 40 and 70 which consist of over 73 per cent of total scores obtained. Accordingly, 20 percent of participants had a score over 70.

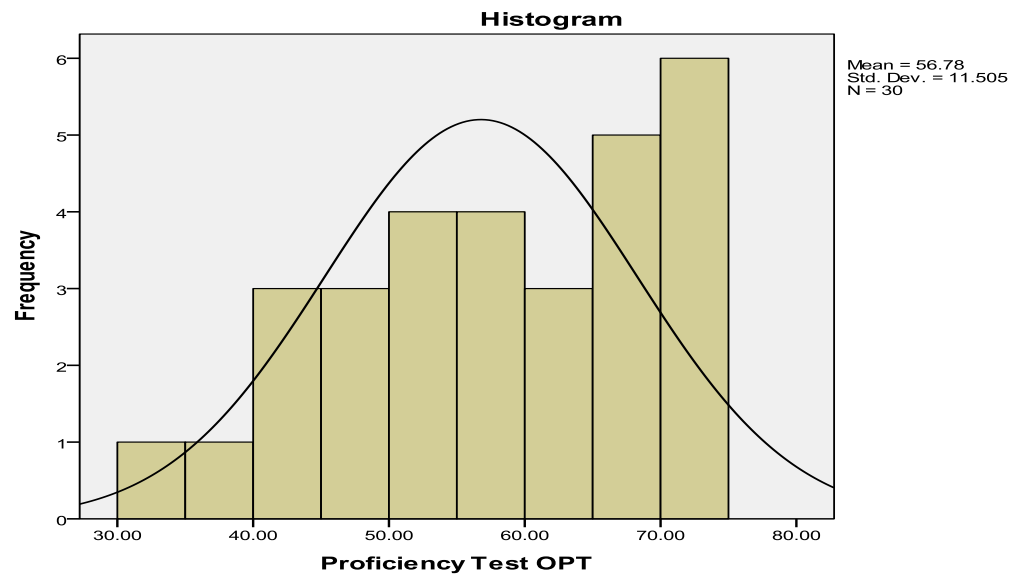

Figure 1. Distribution of Participants in Oxford Placement Test (OPT).

As Table 2 shows, minimum and maximum scores obtained in the Oxford Placement Test were 30 and 73 respectively which suggests a range of almost 43, and a mean of 56.77. The variance for all the scores obtained equals 132.36 with a standard deviation of 11.50 from the mean. 
TABLE II.

STATSITICAL DESCRIPTIVE DATA OF THE PARTICIPANTS IN OXFORD PLACEMENT TEST

\begin{tabular}{|l|l|l|l|l|l|l|l|l|l|}
\hline Test & N & Range & Min. & Max. & Mean & Median & Mode & Variance & Std. Deviation \\
\hline Oxford Placement Test & 30 & 43.33 & 30 & 73.33 & 56.7753 & 58.33 & 50 & 132.364 & 11.50494 \\
\hline
\end{tabular}

Based on the obtained results consistency of items in Oxford Placement Test was measured through K-R 21 and thus its reliability was $(\mathrm{K}-\mathrm{R} 21=0.99)$.

TABLE III.

RELIABILITY OF OXFORD PLACEMENT TEST

\begin{tabular}{|l|l|l|}
\hline \multicolumn{2}{|c|}{ RELIABILITY OF OXFORD PLACEMENT TEST } \\
\hline Number of Students & Number of Items & K-R 21 Method \\
\hline 30 & 60 & 0.9934 \\
\hline
\end{tabular}

The Kolmogorov-Smirnov Test approves the distribution function of the results as normal. The result of the performed test appears in the Table 4.

TABLE IV.

ONE-SAMPLE KOLMOGOROV-SMIRNOV TEST FOR OPT

\begin{tabular}{|l|l|l|}
\hline \multicolumn{3}{|c|}{ ONE-SAMPLE KOLMOGOROV-SMIRNOV TEST FOR OPT } \\
\hline N & Mean & 30 \\
\hline \multirow{2}{*}{ Normal Parameters ${ }^{\mathrm{a}, \mathrm{b}}$} & Std. Deviation & 56.7753 \\
\hline Kolmogorov-Smirnov Z & 11.50494 \\
\hline Asymp. Sig. (2-tailed) & .708 \\
\hline
\end{tabular}

b. Calculated from data.

The following boxplot in Figure 2 visualises the degree of dispersion and skewness in the data, and identifies outliers. It also eases the study of the distributional characteristics of scores in OPT.

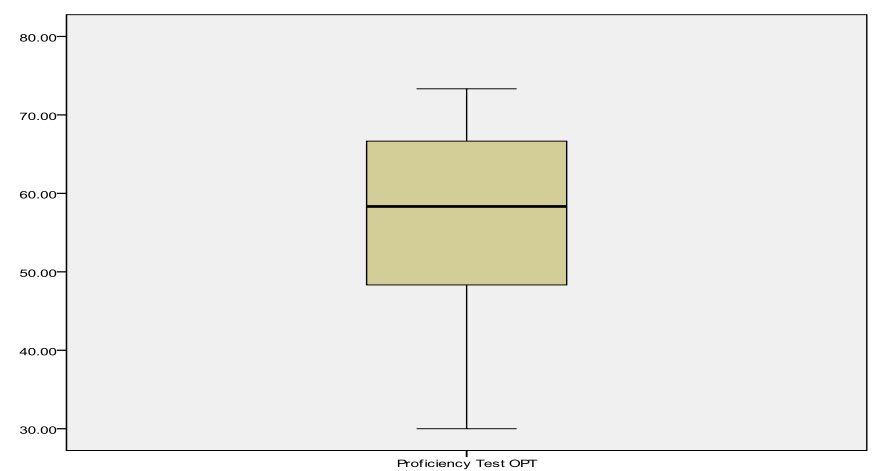

Figure 2. Boxplot for OPT.

According to Figure 2, range of scores in OPT is relatively wide and the lower whisker is a tall one suggesting that $25 \%$ of scores below the lower quartile are dispersed across a wider range compared to upper whisker. The box, however, has a median right in the midpoint of quartile 2 and 3 to show a symmetric dispersion with a small skewedness. It can also be seen from the figure that there is no outlier in the score which implies that all scores lie within the lowest and highest value. This, in turn, suggests that distribution of the population from which sample was taken is normal.

An analytic look at the following figures indicates that distributions of the two tests of inference are bell shaped, thus normal since many scores accumulated in the center.

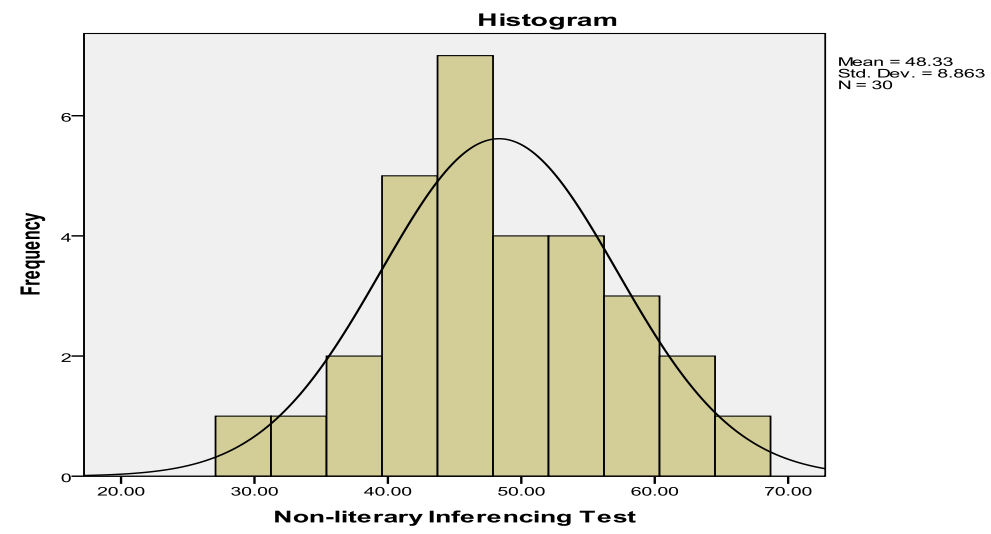

Figure 3. Distribution of participants in non-literary inference test. 


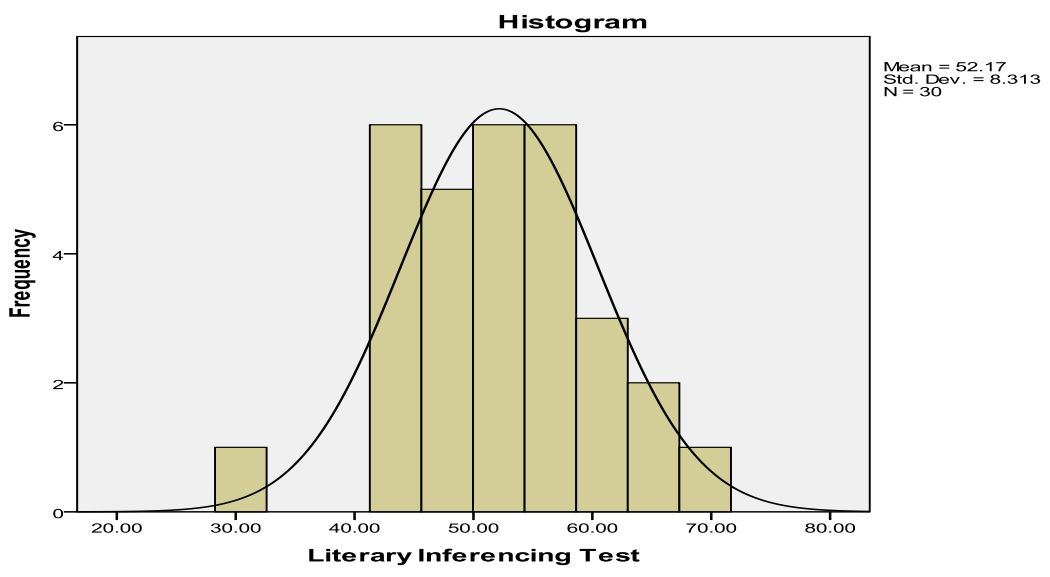

Figure 4. Distribution of Participants in literary inference test.

The following figure depicts the degree of dispersion and skewness in the data, and identifies outliers in non-literary and literary inference tests.

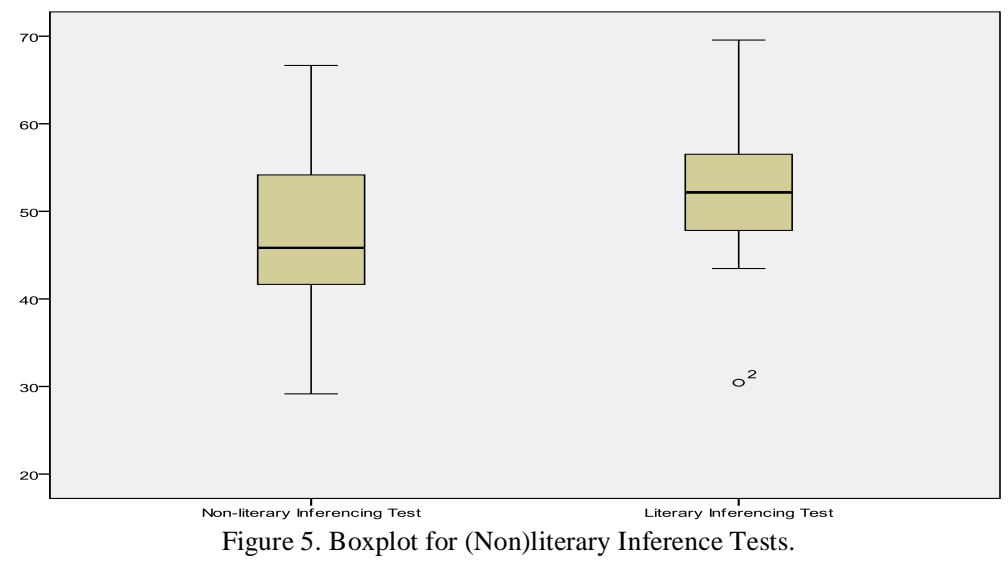

An analytic look at Figure 5 implies that the height of non-literary inference test boxplot is normal, suggesting that distribution of scores is relatively consistent. Lower and upper whiskers are almost equal in size, but the second and third quartiles have different height and the median is closer to lower quartile. This shows that the top 50\% of scores have greater variety. It can also be seen from the figure that there is no outlier in the scores which implies that all scores lie within the lowest and highest value. This, in turn, suggests that distribution of the population from which sample was taken is normal.

The boxplot for literary inference test, however, is situated in the upper part of the scores range. The lower whisker is a short one suggesting that $25 \%$ of scores below the lower quartile are dispersed across a shorter range compared to upper whisker. The box, however, has a median right in the midpoint of quartile 2 and 3 to show a symmetric dispersion. It can also be seen from the figure that there is only one outlier in the score which implies that almost all scores lie within the lowest and highest value. This, in turn, suggests that distribution of the population from which sample was taken is normal.

The obtained mean scores of non-literary (NL) and literary (L) inference tests for total number of participants $(\mathrm{N}=30)$ were $(\mathrm{NL}=48.32, \mathrm{~L}=52.16)$ and a standard deviation of $(\mathrm{NL}=8.86, \mathrm{~L}=8.31)$. Non-literary inference test had a range of 37.50 while the range for literary inference test was 39.13. As the Table 5 demonstrates, the participants' responses to both tests were relatively consistent.

TABLE V.

DESCRIPTIVE STATISTICS OF THE PARTICIPANTS IN(NON)LITERARY INFERENCE TESTS

\begin{tabular}{|l|l|l|l|l|l|l|l|l|l|}
\hline Test & $\mathrm{N}$ & Range & Min. & Max. & Mean & Median & Mode & Variance & Std. Deviation \\
\hline Non-literary Test & 30 & 37.50 & 29.16 & 66.66 & 48.3297 & 45.83 & 45.83 & 78.550 & 8.86282 \\
\hline Literary Test & 30 & 39.13 & 30.43 & 69.56 & 52.1683 & 52.17 & $43.47^{\text {a }}$ & 69.102 & 8.31276 \\
\hline
\end{tabular}

a. Multiple modes exist. The smallest value is shown.

The calculated Kolmogorov-Smirnov test in Table 6 implies the normal distribution of the two tests $(\mathrm{NL}=.791, \mathrm{~L}$ $=.626)$ and the feasibility of the parametric study. 
TABLE VI.

ONE-SAMPLE KOLMOGOROV-SMIRNOV TEST FOR NON-LITERARY INFERENCE TEST

\begin{tabular}{|c|c|c|c|}
\hline & & \begin{tabular}{|l|} 
Non-literary \\
Inferencing Test
\end{tabular} & \begin{tabular}{|l} 
Literary \\
Inferencing Test
\end{tabular} \\
\hline $\mathrm{N}$ & & 30 & 30 \\
\hline \multirow{2}{*}{ Normal Parameters ${ }^{\mathrm{a}, \mathrm{b}}$} & Mean & 48.3297 & 52.1683 \\
\hline & Std. Deviation & 8.86282 & 8.31276 \\
\hline Kolmogorov-Smirnov Z & & .791 & .626 \\
\hline Asymp. Sig. (2-tailed) & & .559 & .828 \\
\hline
\end{tabular}

With regard to the nature of the hypothesis in the present investigation which is mainly concentrated on measuring the correlation (linear dependence) between the two sets of variables - proficiency and inference ability - the researcher collected the quantifiable data from participants by means of Oxford Placement Test, non-literary/literary inference cloze tests. Due to normality of the data, Pearson product-moment correlation coefficient (PPMCC) was conducted. Considering the 0.95 level of significance and p-value <.05, the decision making principle is as follows:

a. If the significance of two-tailed correlation coefficient is less than or equal to (0.05), the null hypothesis is rejected $(p$-value $\leq .05)$.

b. If the significance of two-tailed correlation coefficient is more than (0.05), the null hypothesis is confirmed ( $p$ value > .05).

The hypothesis of this study states that: "There is no relationship between EFL learners' language proficiency and their performance on inference demanding tests." In order to evaluate the strength and direction of relationship between different test scores correlations were computed. Table 7 presents the related data.

TABLE VII.

RELATION BETWEEN LANGUAGE PROFICIENCY AND INFERENCE TESTS

\begin{tabular}{|c|c|c|c|c|}
\hline & & Proficiency Test OPT & $\begin{array}{l}\text { Non-literary } \\
\text { Inferencing Test }\end{array}$ & $\begin{array}{l}\text { Literary Inferencing } \\
\text { Test }\end{array}$ \\
\hline \multirow{3}{*}{ Proficiency Test OPT } & Pearson Correlation & 1 & $857^{* *}$ & $624^{* *}$ \\
\hline & Sig. (2-tailed) & & .000 & .000 \\
\hline & $\mathrm{N}$ & 30 & 30 & 30 \\
\hline \multirow{3}{*}{ Non-literary Inferencing Test } & Pearson Correlation & $.857^{* *}$ & 1 & $390^{*}$ \\
\hline & Sig. (2-tailed) & .000 & & .033 \\
\hline & $\mathrm{N}$ & 30 & 30 & 30 \\
\hline \multirow{3}{*}{ Literary Inferencing Test } & Pearson Correlation & $.624^{* *}$ & $390^{*}$ & 1 \\
\hline & Sig. (2-tailed) & .000 & .033 & \\
\hline & $\mathrm{N}$ & 30 & 30 & 30 \\
\hline
\end{tabular}

The results in Table 7 show that there is a significant relationship between language proficiency and non-literary inference test $(\mathrm{r}=.857, p=.000)$, with a strong and positive correlation. As one would expect from the related literature, there was a positive significant correlation between language proficiency and literary inference test $(\mathrm{r}=.624, p=.000)$, while there is a moderate and positive correlation between the two inference tests at 0.05 level $(\mathrm{r}=.390, p=.033)$. In short, there was a positive and strong relationship between the language proficiency of learners and their ability in answering inference demanding questions; thus, the null hypothesis is also rejected. In the next section, major findings of the present study will be noted.

\section{CONCLUSION}

The present study was set up to confirm or reject the effect of general language proficiency level on how they deal with inference demanding texts. One major issue explored in this study was a possible relationship between EFL learners' language proficiency and their performance on inference demanding tests. Interpreting the findings of correlation coefficient, the researcher was able to conclude that there was a strong and positive relationship between EFL learners' language proficiency and their performance on inference demanding tests. This superior performance of proficient readers over poor ones, when it comes to inference ability, is consistent with most previous research studies (Jenkins, 1986; Phillips, 1989). Based on the analysed data from the current study, it is reasonable to hold with previous studies.

The possible reasons for the superiority of the proficient readers are that they use the facts, the hints, and their prior knowledge to piece together the bits of meaning. The facts and clues lead to assumptions which then lead to conclusions. Thus, poor readers might not extract enough evidence and clues from the text, which in turn can lead to weaker inferences (Pennell, 2002).

In conclusion, it is unquestionable that literature is of great importance in EFL learning since the benefits it serves are numerous as it is a multi-dimensional means to create a safe ground for language learning and teaching. 
APPENDIX A. INFERENCE TESTS

INSTRUCTIONS: Choose the most appropriate answer. You will have 15

\section{minutes.}

Phenomenal Woman by Maya Angelou

Pretty women wonder where my secret lies.

I'm not cute or built to ....1.....a fashion model's size

But when I ...2.... to tell them,

They think I'm ....3.... lies.

I say,

It's in the...4 ... of my arms

The span of my hips,

The stride of my step,

The curl ....5... my lips.

I'm a woman

Phenomenally.

...6.....woman,

That's me.

I walk into ...7 ... room

Just as cool as you please,

...8.... to a man,

The fellows stand or

...9.... down on their knees.

Then they swarm ....10... me,

A hive of honey bees

I...11...,

It's the fire in my eyes,

$\ldots 12 \ldots$ the flash of my teeth,

The swing...13 .... my waist,

And the joy in my ....14...

I'm a woman

Phenomenally.

Phenomenal woman,

....15....'s me.

Men themselves have wondered

What.....16.... see in me.

They try so much

...17.... they can't touch

My inner mystery.

...18.... I try to show them

They say ....19... still can't see.

I say,

It...20... in the arch of my back,

The....21.... of my smile,

The ride of my ....22....

The grace of my style.

I'm ....23.... woman

Phenomenally.

Phenomenal woman,

That's me.
$1 \quad$ A fit

2 A start

C begin

3 A liking

C loving

$4 \quad$ A grasp

C scope

$5 \quad \mathbf{A}$ in

C of

6 A phenomenal

C magnificent

$7 \quad$ A the

C my

8 A next

C first

$9 \quad$ A drop

C come

10 A around

C aloud

11 A deny

C say

$12 \quad A$ and

C with

13 A in

C on

14 A eyes

C hands

15 A this

C she

16 A people

C enemies

17 A however

C but

18 A when

C as

19 A people

C enemies

20 A is

C isn't

21 A shine

C love

22 A bikes

C cheeks

23 A the

C a
B meet

D suit

B commence

D mean

B telling

D saying

B range

D reach

B at

D on

B wondrous

D terrific

B a

D this

B a

D then

B go

D fall

B above

D about

B tell

D cry

B but

D or

B at

D of

B feet

D heart

B it

D that

B friends

D they

B while

D whenever

B if

D whenever

B friends

D they

B 's

D is not

B sun

D fun

B breasts

D horses

B that

D this 
INSTRUCTIONS: Choose the most appropriate answer. You will have 20 minutes.

Why the Yogic way for food?

Yoga is the only science that has placed great emphasis on food over centuries. In fact, there is a whole branch - ................. Anna Yoga devoted to food for health and ......2........

Over centuries, Yoga has developed a concept ........... a balanced wholefood diet and an eating .............. These principles of good eating use powerful .............. which help in maintaining a strong and ......6.......body, a stress-free mind and a positive .....7....... within this mixed-up world.

Never has .....8....... Yogic philosophy of a balanced whole-food diet been $\ldots \ldots . . . . . .$. more than today when $97 \%$ of all $\ldots \ldots . .10 \ldots \ldots$ disorders can be traced to a faulty .......11 ....... and diet.

It has been observed that (East) $\ldots \ldots .12 \ldots \ldots$ civilizations suffer least from bowel problems, constipation, ........13....... and other food related disorders such as ......14........ Do you know why? Because the Indian $\ldots \ldots .15 \ldots \ldots$ of cooking and eating draws heavily from $\ldots . .16 \ldots \ldots$ yogic philosophy of eating!

Yoga does not ....17..... food into vitamins, minerals, protein etc..The .....18.....philosophy is that the true benefits of these ......19..... can be had only when they are .....20...... isolated but are kept as much in their natural form as possible.

The key to .....21.... health is to have a balanced wholefood .....22....... A balanced diet ensures that all the .....23...... of digestion work smoothly-absorption, assimilation and elimination. .......24....... balanced whole-food diet ensures a healthy you!

\begin{tabular}{|c|c|c|}
\hline \multirow[t]{2}{*}{1} & A dubbed & B called \\
\hline & C named & D denominated \\
\hline \multirow[t]{2}{*}{2} & A delight & B gratification \\
\hline & $\mathbf{C}$ pleasure & D happiness \\
\hline \multirow[t]{2}{*}{3} & $A$ in & $\mathbf{B}$ at \\
\hline & $\mathbf{C}$ on & D of \\
\hline \multirow[t]{2}{*}{4} & A philosophy & B possibility \\
\hline & C philosophies & D possibilities \\
\hline \multirow[t]{2}{*}{5} & A techniques & B approaches \\
\hline & C approaches & D ways \\
\hline \multirow[t]{2}{*}{6} & A healthier & B healthy \\
\hline & C healthily & D health \\
\hline \multirow[t]{2}{*}{7} & A feeling & B atmosphere \\
\hline & C spirituality & D belief \\
\hline \multirow[t]{2}{*}{8} & A that & B such \\
\hline & C -- & D this \\
\hline \multirow[t]{2}{*}{9} & A required & B demanded \\
\hline & C needed & D desired \\
\hline \multirow[t]{2}{*}{10} & A healthier & B healthiest \\
\hline & C healthily & D health \\
\hline \multirow[t]{2}{*}{11} & A nutrition & B nutriment \\
\hline & $\mathbf{C}$ nourishment & D nutrient \\
\hline \multirow[t]{2}{*}{12} & A Swedish & B Indian \\
\hline & C Canadian & D Belgian \\
\hline \multirow[t]{2}{*}{13} & A indigestion & B headache \\
\hline & C fatigue & D backache \\
\hline \multirow[t]{2}{*}{14} & A obesity & B fatness \\
\hline & C bigness & D heaviness \\
\hline \multirow[t]{2}{*}{15} & A philosophy & B lifestyle \\
\hline & C logic & D possibility \\
\hline \multirow[t]{2}{*}{16} & A -- & $\mathbf{B}$ this \\
\hline & C the & D such \\
\hline \multirow[t]{2}{*}{17} & A provide & B analyze \\
\hline & C dissect & D synthesize \\
\hline \multirow[t]{2}{*}{18} & A yoga & B yogi \\
\hline & C yogic & D -- \\
\hline \multirow[t]{2}{*}{19} & A components & B ingredients \\
\hline & C elements & D constituents \\
\hline \multirow[t]{2}{*}{20} & A never & B not only \\
\hline & C -- & D not \\
\hline \multirow[t]{2}{*}{21} & A true & B real \\
\hline & C truly & D really \\
\hline \multirow[t]{2}{*}{22} & A style & B nourishment \\
\hline & C improvement & D diet \\
\hline \multirow[t]{2}{*}{23} & A aspects & B sections \\
\hline & C faculties & D means \\
\hline \multirow[t]{2}{*}{24} & A the & B a \\
\hline & C one & D -- \\
\hline
\end{tabular}

\section{REFERENCES}

[1] Aguero, D. A. (n.d.). Using literature in EFL classes for teachers. Federal University of Santa Catarina / CNPq.

[2] Bagherkazemi, M. \& Alemi, M. (2010). Literature in the ESL/EFL classroom: Consensus and controversy. Linguistic and Literary Broad Research and Innovation, 1.1, 1-12.

[3] Bhuvaneswari, V., \& Jacob, R. (2011). Language acquisition through short stories for second language learners. Studies in Literature and Language, 3.3, 156-158. DOI: 10.3968.

[4] Cain, K., Oakhill, J. V., Barnes, M. A., \& Bryant, P. E. (2001). Comprehension skill, inference-making ability, and their relation to knowledge. Memory \& Cognition, 29.6, 850-859.

[5] Carter, R. (1997). Investigating English discourse: Language, literacy and literature. London and New York: Routledge.

[6] Duff, A., \& Maley, A. (2003). Literature (12 ${ }^{\text {th }}$ ed.). Oxford: Oxford University Press.

[7] Erkaya, O. R. (2005). Benefits of using short stories in the EFL context. Asian EFL Journal, 1-13.

[8] Gajdusek, L. (1988). Toward wider use of literature in ESL: Why and how. TESOL Quarterly, 22.2, 227-257.

[9] Gordon, J. A., \& Harding, P. (2007). Essential Reading for IELTS. Higher Education Press. http://www.topsage.com (accessed 26/1/2009).

[10] Khatib, M., \& Nourzadeh, S. (2011). Some recommendations for integrating literature into EFL/ESL classrooms. International Journal of English Linguistics, 1.2, 258-263. DOI: 10.5539.

[11] Khatib, M., Rezaei, S., \& Derakhshan, A. (2011). Literature in EFL/ESL classroom. English Language Teaching, 4.1, $201-208$. Retrieved from www.ccsenet.org/elt (accessed 18/07/2012).

[12] Kispal, A. (2008). Effective Teaching of Inference Skills for Reading. National Foundation for Educational Research. Research Report DCSF-RR031. 
[13] Kopitski, M. (2007). Exploring the teaching of inference skills (Unpublished Master's thesis). Hamline University, Minnesota, the USA.

[14] Lazar, G. (1994). Using literature at lower levels. ELT Journal, 48.2, 115-124.

[15] MacKay, S. (1982). Literature in the ESL classroom. TESOL Quarterly, 16.4, 98-105.

[16] Pennell, D. (2002). Explicit Instruction for Implicit Meaning: Strategies for Teaching Inferential Reading Comprehension. Considerations: Inferential Comprehension, T/TAC W\&M, 1-800-323-4489, 1-16.

[17] Phillips, L. M. (1989). Developing and validating assessments of inference ability in reading comprehension. Technical Report No. 452.

[18] Povey, J. F. (1967). Literature in TESL programs: The language and the culture. TESOL Quarterly, 1.2, 40-46.

[19] Ronnqvist, L., \& Sell, R. D. (1994). Teenage books for teenagers: Reflections on literature in language education. ELT Journal, $48.2,125-132$

[20] Savvidou, C. (2004). An integrated approach to teaching literature in the EFL classroom. The Internet TESL Journal, X, 12. Retrieved from http://www.iteslj.org (accessed 22/07/2012).

[21] Thom, N. T. T. (2008). Using literary texts in language teaching. VNU Journal of Science, Foreign Language, 24, $120-126$.

[22] Thornbury, S. (2006). An A-Z of ELT. Oxford: Macmillan.

[23] Walls, E. J. (1986). A study of grade level and reader ability differences in inferential comprehension of stories having static and dynamic characters (Doctoral dissertation). Retrieved from Proquest Dissertations and Theses. (UMI 8627524). Temple University Graduate Board, Michigan, the USA.

[24] Widdowson, H. G. (1996). Comment: Authenticity and autonomy in ELT. ELT Journal, 50.1, 67-68.

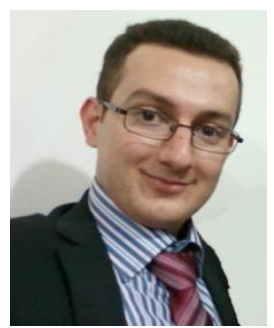

Reza Mokhtari holds an M.A. in TEFL from Azad University, Science and Research Branch (Kermanshah, Iran, 2012). He has been an IELTS instructor since (2004). His main areas of interest include applied linguistics and ESP. He has published and presented papers in these areas.

Natasha Pourdana is an assistant professor at Gyeongju University, Republic of Korea. Dr. Pourdana received her Ph.D at Islamic Azad University of Science and Research Branch. Her main area of interest is testing and she has published several books and many national and international articles.

Omid Varzandeh is an assistant professor at Islamic Azad University, Sanandaj branch, Iran. Dr. Varzandeh received his B.A. in English Translation from Islamic Azad University of Hamedan and obtained his M.A. and Ph.D. in English Literature from University of Pune, India. 